\title{
ОТЛИЧИТЕЛЬНЫЕ ОСОБЕННОСТИ МЕТОДИКИ ПРЕПОДАВАНИЯ ЯПОНСКОГО ЯЗЫКА В ШКОЛЕ
}

Андреева Елена Петровна

преподаватель японского языка

МОУ гимназия 41

\begin{abstract}
Аннотация: В статье приведен анализ методики преподавания японского языка, обоснована необходимость изучения японского языка в России, выявлены особенности и сложности преподавания в средней школе, которые влияют на процесс обучения, проведен также анализ имеющейся учебной литературы для школьников и приложений.
\end{abstract}

\section{DISTINCTIVE FEATURES OF THE TECHNIQUE TEACHING JAPANESE AT SCHOOL}

\section{Andreeva Elena Petrovna}

Abstract: The article analyzes the methodology of teaching the Japanese language, substantiates the need to study the Japanese language in Russia, identifies the features and difficulties of teaching in secondary schools that affect the learning process, and analyzes the available educational literature for schoolchildren and applications.

В настоящее время Россия активизирует контакты со странами АТР в экономической, культурной, образовательной и других сферах. Отношения сотрудничества между Японией и Россией, выйдя за рамки двусторонних отношений, развиваются на региональном уровне, а также на глобальном уровне; развитие в дальнейшем такой тенденции отвечает стратегическим интересам Японии и России. Такая позиция утверждена третьим разделом «Японо-российского плана действий» под названием «Сотрудничество на международной арене: «Продвижение диалога и действия в качестве стратегических партнеров»»» [1]. Россия и Япония имеют геополитически выгодное расположение для развития тесных торгово-экономических, культурных, образовательных, научных связей. 
Подготовка специалистов со знанием японского языка, несмотря на ее смещение в сторону китайского языка, востребована в образовательной теории и практике. Как отмечают российские методисты, языки с иероглифической письменностью имеют особенности, которые необходимо учитывать при организации учебного процесса, Л.Т. Нечаева в своих исследованиях отразила особенности преподавания японского языка в России [2].

Японский язык считается одним из самых сложных для изучения иностранных языков в мире. Это связано с трудностями в овладении японской иероглифической письменностью, грамматическими правилами, лексическим составом языка с большим количеством синонимов и омонимов, особенностями произношения, различными стилями речи.

Письменность японского языка представляет собой смешанный тип письма, состоящий из иероглифов, заимствованных японцами в древности из Китая, и двух слоговых азбук хирагана и катакана. Еще одним отличительной особенностью японского языка является тонизация. Разница в высоком и низком тоне часто бывает едва уловимой на слух, поэтому без наглядной иллюстрации того, на что именно надо обращать внимание при прослушивании и повторении за диктором, школьники этой разницы просто не замечают.

Изучение японской письменности оттягивает на себя огромную долю аудиторного времени. В связи с наличием двух азбук и значительного количества иероглифов, каждый из которых имеет по несколько чтений, удельная доля времени, затрачиваемого на обучение чтению и письму на японском языке, значительно выше, чем, например, при обучении чтению и письму на английском. Удельный вес аудирования оказывается относительно низким, но при этом трудностей, возникающих у школьников при аудировании японских текстов, достаточно много [3, с. 45].

На начальном этапе идет формирование основных умений и навыков в области чтения, орфографии, перевода, восприятия на слух иноязычной речи, грамматического и структурного оформления устной и письменной речи. Начальный этап является наиболее ответственным и сложным в изучении японского языка. Это связано с трудностями усвоения большого объема запоминаемой информации (иероглифики, лексики, грамматических конструкций), с непониманием неадаптированной под начальный уровень японской речи на слух. 
Тема распределения и баланса различных видов речевой деятельности на уроках иностранного языка никогда не затрагивалась в российской методической литературе применительно к обучению школьников японскому языку.

В последние годы проблема аудирования все больше привлекает внимание методистов. Известно, что в практике преподавания методика обучению аудированию наименее разработана. Добиться равномерного развития навыков устной речи и аудирования можно только при условии применения системы упражнений для развития понимания устной речи в естественных условиях общения. Многие студенты, даже те, кто хорошо читает и переводит, испытывают затруднения при слушании и понимании естественной речи японцев. Аудирование является одним из самых сложных видов речевой деятельности. Одна из практических задач преподавателя обучение студентов пониманию и воспроизведению речи на японском языке в условиях, приближенным к реальным. Аутентичные материалы в обучении аудированию создают иллюзию приобщения к естественной языковой среде, что является главным фактором в успешном овладении языком. В ВШЭ при обучении японскому языку студентов в ВУЗе на аудирование выделяется 30-40 мин. в неделю при нагрузке 8 часов в неделю. Ситуация в школе еще сложнее: из двух-трех часов в неделю (данные анкетирования учителей японского языка г. Москвы), посвятить аудированию удается лишь несколько минут, и этого явно недостаточно в условиях столь далеких от языковой среды [4, с. 17-22].

Для преодоления названных трудностей на занятиях японским языком преподавателем могут быть использованы различные традиционные методы обучения, которые в образовательном процессе вуза классифицируются на методы готовых занятий и исследовательские методы (Б.Х. Всехсвятский); активные и пассивные (Е.Я. Голант); репродуктивные и продуктивные (И.Я. Лернер и М.Н. Скаткин). Специфика обучения на языковых направлениях требует сочетания указанных групп методов, в зависимости от содержания изучаемого материала и этапа обучения иностранному языку. Например, при введении и объяснении нового лексического, иероглифического и грамматического материала, закреплении знаний и совершенствовании умений уместны репродуктивные методы, когда роль преподавателя более активна, чем студента: объяснение, рассказ, беседа, демонстрация, упражнения для выработки динамического стереотипа. Для 
побуждения учащихся к интенсивной мыслительной, практической, творческой деятельности необходимы проблемно-поисковые методы обучения: специальные исследовательские задания, которые выполняются индивидуально или группой студентов; сформулированные неразрешенные вопросы (проблемы) по учебной теме; задания сбора теоретического материала или эмпирического исследования. Также используются имитационные методы: ситуационные решения, деловые игры, разыгрывание ролей, «мозговая атака».

На начальном этапе неотъемлемой частью подготовки являются методы практического обучения, т.к. обучение иностранному языку не может проходить без многократных повторений, упражнений, тренировок. Формирование умений происходит в процессе выполнения учащимися соответствующих заданий: подстановочных упражнений; перевода с изучаемого иностранного языка на родной и наоборот; пересказа прочитанного на родном и иностранном языках; ответов на вопросы по изучаемой тематике на иностранном языке; написания сочинений на изучаемом языке по образцу и т.п. [5, с. 184-189].

В России получили широкую известность фестивали японской культуры, косплеи, выставки и концерты, посвященные культуре Японии, и др. Одним из условий развития иноязычной коммуникативной компетенции студентов, изучающих японский язык, - это создание иноязычной среды, направленной на развитие у обучающихся профессиональных компетенций.

Хотелось также отметить роль внеаудиторных мероприятия, направленных на развитие коммуникативной компетенции, которые способствуют повышению мотивации студентов к изучению японского языка, более глубокому пониманию особенностей японской культуры, этикета, межкультурной коммуникации.

Внеаудиторная работа может включать в себя следующие виды деятельности:

- конкурсы устных выступлений на японском языке,

- фестивали японской культуры,

- мастер классы и конкурсы по каллиграфии,

- день японского языка для школьников,

- конкурс традиционной новогодней открытки,

- конкурс на создание обложки к книге «Японская сказка», 
- мастер классы, связанные с кимоно, чайной церемонией, японскими видами рукоделия, икебана, различными видами спорта, музыкальными инструментами, оригами,

- $\quad$ японские шахматы, игра «Го» и др.

Методы практического обучения могут включать не только многократные повторения или упражнения изучаемых лексических и грамматических конструкций, но и способствовать поддержанию положительной мотивации учащихся начального этапа обучения, повышению интереса к японскому языку и Японии, выступать как средство изучения и закрепления теоретических и практических аспектов сложного восточного языка [5].

Одним из возможных вариантов повышения эффективности занятий является использование наглядности. Тема использования наглядности в обучении и воспитании описывалась еще в работах Коменского Я.А. (1592-1670), Песталоцци И.Г. (1746-1827), а в более поздние времена, в советской и российской педагогике, принцип наглядности являлся одним из основных дидактических принципов. Этот принцип описан в трудах Ушинского К.Д., Сухомлинского В.А., Выготского Л.С., Занкова Л.В. и др.

Наглядность - одна из разновидностей опор при изучении иностранного языка. В книге «Урок иностранного языка» Е.И. Пассов отмечает: «Полной классификации опор пока еще нет» [6], но обычно выделяют две большие группы опор - вербальные и иллюстративные. Рассмотрим использование иллюстративных опор. Наряду с иллюстрациями это могут быть схемы, надписи, графики, диаграммы и т.п.

Применительно к японскому языку необходимо отметить, что зрительное восприятие является очень важным элементом японской культуры. Иероглифическая письменность, любовь к комиксам манга, особые взгляды японцев на внешние формы красоты - все это свидетельства того, что в Японии гораздо сильнее, нежели в других странах, мир воспринимается «через глаза». Картинки и схемы в Японии используются практически везде, а для людей с ослабленным зрением создана необходимая инфраструктура - от кнопок в лифте до надписей на продуктах на азбуке Брайля. Наверное, больше ни в одной стране не уделяется столько внимания зрительному восприятию.

Иллюстрации способствуют задерживанию информации в оперативной памяти, тем самым способствуя ее развитию. Гальскова Н.Д. и Гез Н.И. в «Теории обучении иностранным языкам» отмечают, что «чем сложнее 
материал, тем предпочтительнее зрительные опоры». При обучении говорению Пассов Е.И. рекомендует соотношение использования опор как $1: 5 / 1: 3[3$, c. 46$]$.

Японский язык в российских школах преподается в качестве второго или третьего иностранного языка. При ограниченном количестве учебного времени очень важно использовать все имеющиеся ресурсы для обучения школьников японскому языку с максимальной эффективностью.

В настоящее время в Японии при изучении японского языка основное внимание уделяется освоению коммуникационными навыками, которые в свою очередь делятся на 4 составляющие: усвоение грамматического материала, социолингвистические навыки, способность вести беседу и стратегические навыки. Зная только грамматический материал, невозможно на должном уровне общаться на иностранном языке. Необходимы и знание реалий, и способность грамотно построить беседу в зависимости от ситуации с тем, чтобы понять собеседника и в то же время доступно донести до него свои мысли. Кроме того, владение стратегическими навыками помогает сориентироваться в ситуации, когда не знаешь, как правильно сформулировать свою мысль.

По мнению японцев, развить коммуникационные навыки на начальном этапе изучения японского языка можно, построив занятие по следующей схеме: введение, базовые упражнения и практические упражнения. Однако при введении новой грамматической формы или конструкции более эффективным считается не просто ее озвучивание и объяснение преподавателем, а активное участие учащихся, в результате которого они сами делают предположения, пытаются озвучить новую форму и понять ее смысл. При этом предлагается использовать наглядные материалы, например, картинки с изображением различных реальных ситуаций, в которых может быть использована та или иная форма или конструкция. При таком способе объяснения поддерживается интерес учащихся, что позволяет сделать процесс обучения более эффективным.

При введении новой грамматики вместо стандартного объяснения преподавателя рекомендуется активное участие учащихся, когда они сами пробуют образовать ту или иную грамматическую форму или конструкцию. Для лучшего закрепления материала, усвоения введенных форм можно предлагать учащимся различные языковые игры, ролевые игры и т.д. 
Для овладения умениями устной речи на всех уровнях (от начального до высокого) предлагаются такие формы работы: интервью, выступление на заданную тему, обсуждение и ролевые игры. Для начального уровня можно предлагать темы: как добираетесь до школы, сколько времени уходит на дорогу, распорядок дня. Для обсуждения - что подарить другу на день рождения, в какой парк, кафе пойти. Для более продвинутых уровней проблема окружающей среды, будущая работа, проведение свободного времени и т.д. После завершения этих видов работы учащимся предлагается оценить уровень друг друга и свой собственный [7].

Новый этап быстрого развития научного прогресса в обществе, ориентация сегодняшней России на человека с высоким интеллектуальным потенциалом требуют также изменений в учебно-педагогическом процессе, в методах, формах и видах образования и обучения. Для этого необходимо создание такой высокоэффективной системы обучения, которая обеспечила бы возможность постоянного получения новых знаний, умений и навыков в обработке постоянно увеличивающегося информационного потока.

Повсеместное внедрение современной компьютерной техники и средств передачи информации в различные сферы человеческой деятельности привело открытию широких перспектив в области обучения иностранным языкам, в частности японскому языку.

Использование ИКТ в учебном процессе обучения японскому языку позволяет организовать активную познавательную деятельность учащихся, оптимизировать учебный процесс, увеличить объем информации, получаемой на занятии, повысить мотивацию, создать новые возможности для развития внутреннего мира обучаемого, стимулировать его творческие способности. Все это ведет к коренным изменениям учебной деятельности, возникновению ее новых видов и форм.

Современные технологии предполагают использование уникальных возможностей компьютерной информационной среды, включающей на современном уровне гипертекстовые электронные учебники, базы данных, мультимедиа, электронные коммуникации и т.д. [8].

C каждым годом образовательные программные приложения на смартфонах набирают все большую популярность, все выше становится их качество исполнения. И японский язык не стал исключением для таких приложений. Например, словари: Google переводчик, EJLookup, Japanese Dictionary, Translate.ru, ЯРКСИ и др. Обучающие программные приложения: 
приложения Японского Фонда: Kanji Memory Hint, Hiragana Memory Hint, Katakana Memory Hint, Study Japanese, みんなの日本語, L-lingo. Японский язык, JLPT Practice N1-N5 и др.

Данные программы удобны мобильностью и возможностью их применения в свободное время. Обучающие программы условно можно разделить на несколько групп: для начинающих, для продолжающих, для сдачи JLPT, для преподавателей.

В основном обучающие программы для начинающих нацелены на тех, кто желает изучить начальные базовые слова и грамматику в короткие сроки. Данные приложения используют визуальную, в виде картинок, и аудиобазы, чтобы запоминание изучающего было более быстрым и непринужденным [9].

В связи с введением новых стандартов в преподавании японского языка, целесообразно рассмотреть, насколько эти нововведения отражены в учебных пособиях, наиболее популярных в нашей стране. Для обучения в школе, вузе или на языковых курсах не существует единых учебников и все зависит от выбора самого преподавателя. Почти одинаковой популярностью пользуются как учебники японских издательств, так и российские. До недавнего времени большой популярностью на начальном этапе обучения (приблизительно до уровня А2) пользовались российский учебник Л.Т. Нечаевой «Учебник японского языка для начинающих» (в двух частях) (2011) и учебник японского издательства «Minna no nihongo» (в двух частях) [10]. Если посмотреть мировую практику, то преобладающее число стран обучают японскому языку на основе учебников, созданных в Японии на японском языке или на английском [11].

В связи с тем, что на сегодняшний день нет учебника для изучения японского языка в средней школе, оснащенный хорошим аудио курсом и иллюстрациями к нему, существует необходимость обращаться к японским изданиям для детей. Отчасти можно пользоваться учебниками, рассчитанными на взрослую аудиторию, но при этом следует проявлять осторожность: как видно из популярных учебников «Minna no nihongo», «Marugoto» и т.п., часто главные персонажи курят или выпивают сакэ.

Основным недостатком практически всех российских учебников по японскому языку является большое количество грамматико-переводных упражнений и «малое количество (или полное отсутствие) творческих и коммуникативных упражнений» [12, с. 151]. Составленные полностью на русском языке упражнения и задания к ним не мотивируют к дальнейшему 
совершенствованию языка в области иероглифики и не дают преодолеть психологический барьер, который непременно возникает у учащихся на начальном этапе знакомства с иероглифической системой письма.

Учебники японских издательств, в том числе Minna no Nihongo, в большей степени направлены на снятие психологического барьера при первом знакомстве с японским языком и больше подходят для изучения языка на дополнительных курсах, чем российские учебники. Тем не менее, большинство из них слишком адаптировано под иностранцев и использует не аутентичные материалы, что в дальнейшем не дает возможности работать с не учебными текстами и не позволяет вести беседу с носителями языка в реальных ситуациях. Minna no Nihongo дает большое количество языковых упражнений, которые позволяют отработать весь предложенный лексикограмматический материал, но открытым остается вопрос, смогут ли применить свои знания на практике в реальном общении. Данный учебник вполне отвечает своей первоначальной задаче - позволить учащимся подготовиться к сдаче теста JLPT, однако этого недостаточно для успешного овладения языком на современном этапе языкового образования.

Ярким учебником является видеокурс «Эрин бросает вызов» - история о девочке Эрин, приехавшей в Японию и попадающей в разные ситуации. Основная цель курса - повысить интерес учащихся к изучению японского языка и к японской культуре. Его особенностью является то, что в нем использован реальный язык, на котором говорит молодое поколение. Кроме того, в отличие от других пособий по японскому языку, которые знакомят, в основном, с традиционной Японией, в этом курсе охвачено большое количество тем, представляющих интерес для молодого поколения, интересующегося современными аспектами японской жизни (мода, мобильные телефоны, покупки, подработка). Вместе с тем, в пособии содержатся также упражнения для закрепления пройденного грамматического материала. Разделы курса короткие, длятся всего несколько минут, поэтому их можно использовать в любое время на уроке, в любой последовательности и на разных уровнях. Учащиеся также могут самостоятельно проходить этот курс в Интернете (www.erin.ne.jp). В нем можно найти и игры, и тесты [7].

«Genki» - базовый учебник японского языка на начальном этапе обучения, написанный японскими авторами [13]. Для иероглифической практики используется приложение к нему “Kanji. Look and learn”, состоящее из учебника, где даются иероглифы, порядок их написания, употребление, и 
рабочей тетради с практическими упражнениями. В пособии иероглиф рассматривается как своеобразное изображение, и дается расшифровка этого изображения на японском и английском языке.

Кроме учебников по иероглифике, написанных специально для иностранцев, можно использовать пособия, созданные для японских детей, учащихся младших классов, приступающих к изучению иероглифов. Во многих из них использована манга, помимо порядка написания, чтений, употребления в словах, словосочетаниях и предложениях, предлагаются интересные упражнения в виде кроссвордов, ребусов, лабиринтов [14].

Учебник японского языка Танака Нэко для детей М.Р. Голомидовой. Состоит из двух частей. Каждая из частей посвящена изучению одной азбуки и различным аспектам грамматики, есть аудиоматериалы, в каждом уроке даются иероглифы, само их написание, тексты. Имеются сведения о культуре самой Японии, например, что такое бонсай, аниме, сведения о японских городах и др. Минус данного учебника - это медленный темп освоения.

Хотелось бы также отметить учебное пособие для учащихся общеобразовательных учреждений Майдоновой С.В., Ядрышниковой М.В. под редакцией Нечаевой Л.Т. «Японский язык» 5-6 класс. Пособие предназначено для обучения японскому языку со стартового уровня. Содержание учебника и подчеркнутая ориентация на развитие мотивации учеников к изучению иностранного языка соответствует ФГОС ООО и примерным программам по иностранным языкам для 5-6 класса общеобразовательных учреждений [15].

В соответствии с новыми стандартами Японский Фонд выпустил новый учебник «Marugoto». Целью данного учебника является использование японского языка для реального общения, в реальных жизненных ситуациях. Это состоит не только в том, чтобы улучшить знания грамматики и построения предложений. Can-dos - это цели, которые показывают, что обучающийся может делать в каких ситуациях [16].

Учебник рассчитан на освоение программы, разбитой на шесть уровней владения языком (А1 - С2), что соответствует шкале критериев уровня оценивания владения языком по шкале оценивания CEFR. На данный момент выпущен комплект учебников, рассчитанных на освоение японского языка с начального уровня до среднего (A1 - B1). Для каждого уровня предлагается две книги «Rikai» и «Katsudo». «Часть «Rikai» - это учебник для изучения языковых компетенций, на которых основано повседневное общение. Часть 
«Katsudo» - это учебник для изучения способов коммуникации, цель которого привить обучающемуся способность к общению в повседневной жизни. «Rikai» и «Katsudo» можно использовать по отдельности или вместе.

Японские учебники для начинающих раньше были сосредоточены на моделях предложений, но теперь больше внимания уделяется темам общения, которые вводятся с помощью простых языковых моделей на начальном уровне, а затем повторно вводятся и усиливаются на среднем или продвинутом уровне с вариациями и сложными моделями выражений [17]. Marugoto основывается на принципе автономного обучения - принципе, который особо подчеркивает CEFR, - предлагая широкий спектр дополнительных материалов и мероприятий на своем веб-сайте www.marugoto.org.

Таким образом, исходя из рассмотренных выше учебников, можно сделать вывод, что учебник «Marugoto» является отражением наиболее равномерного развитие всех видов речевой деятельности и необходимых для возможности успешного применения своих знаний на практике навыков и умений.

Подводя итог, можно сделать вывод, что обучение японскому языку в рамках дополнительного образования должно иметь ярко выраженную коммуникативную и культурологическую направленность, при которых происходит усвоение не системы языка, а системы языковых средств, необходимых ученикам для использования в той или иной сфере общения [18, с. 72]. При обучении японскому языку в средней школе в качестве факультатива важно развивать и умения чтения и письма, а также умения и навыки говорения и аудирования.

В целом методика преподавания японского языка пытается интегрировать в обучение применяемые в методике преподавания иностранного языка наиболее эффективные методы и технологии. В настоящее время происходит активное внедрение ИКТ технологий на всех уровнях образования, в том числе и в преподавании японского языка. Это показывает позитивную динамику развития методики преподавания японского языка.

\section{Список литературы}

1. Посольство Японии [Электронный pecypc]. https://www.ru.embjapan.go.jp/itpr_ru/cooperate.html (дата обращения 07.05.2021). 
2. Нечаева Л.Т. Японский язык в вузах России // Преподаватель XXI век № 3. 2015. С. 43-49. [Электронный pecypc]. URL: https:// cyberleninka.ru/article/n/yaponskiy-yazyk-v-vuzah-rossii (дата обращения 07.05.2021).

3. Мизгулина М.Н. Использование наглядности при обучении школьников аудированию на японском языке // Современное педагогическое образование № 2018. [Электронный pecypc]. URL: https://cyberleninka.ru/ article/n/ispolzovanie-naglyadnosti-pri-obuchenii-shkolnikov-audirovaniyu-nayaponskom-yazyke (дата обращения 07.05.2021).

4. Лазарева Д.С. Аудирование в рамках преподавания разговорного аспекта // Японский язык в вузе: актуальные проблемы преподавания № 2.2009. С. 17-22. [Электронный pecypc]. URL:https://studylib.ru/doc/ 4063778/audirovanie-v-ramkah-razgovornogo-aspekta (дата обращения 07.05.2021).

5. Старченко Е.В. Методы практического обучения японскому языку на начальном этапе языковой подготовки в вузе // Педагогика: традиции и инновации : материалы IV Междунар. науч. конф. (г. Челябинск, декабрь 2013 г.). С. 184-189. [Электронный ресурс]. URL: https://moluch.ru/conf/ped/ archive/98/4497/ (дата обращения: 07.05.2021).

6. Пассов Е.И., Кузовлева Н.Е. Основы коммуникативной теории и технологии иноязычного образования: методическое пособие преподавателей русского языка как иностранного. М.: Русский язык. Курсы, 2010. 568 с.

7. Лазарева Д.С. О новых подходах в Японии к преподаванию японского языка как иностранного // Японский язык. Методика преподавания японского язык. № 2010. С. 71-77. [Электронный pecypc]. URL: https:// publications.hse.ru/chapters/113638690 (дата обращения 07.05.2021).

8. Котова Аяко, Герасимов А.П. Новое в преподавании японского языка // Известия Восточного института № 2000. С. 234-238. [Электронный pecypc]. URL: https://cyberleninka.ru/article/n/novoe-v-prepodavanii-yaponskogoyazyka (дата обращения 07.05.2021).

9. Калюжная Н.И. Японский язык и программы OC ANDROID // Перспективы развития информационных технологий № 2014. [Электронный pecypc]. URL: https://cyberleninka.ru/article/n/yaponskiy-yazyk-i-programmy-osandroid (дата обращения 07.05.2021).

10. Ефимова С.К. Направления реализации методики обучения японскому языку студентов языкового ВУЗа Республики Саха (Якутия) // Педагогическое образование в России. № 6.2019. С. 102-107. 
[Электронный pecypc]. URL: https://cyberleninka.ru/article/n/napravleniyarealizatsii-metodiki-obucheniya-yaponskomu-yazyku-studentov-yazykovogo-vuzarespubliki-saha-yakutiya (дата обращения 07.05.2021).

11. Котова Т.В. О современном состоянии преподавания японского языка в мире // Известия Восточного института № 1994. С. 187-190. [Электронный pecypc]. URL: https://cyberleninka.ru/article/n/o-sovremennomsostoyanii-prepodavaniya-yaponskogo-yazyka-v-mire (дата обращения 07.05.2021).

12. Степанова А.Д. Проблема выбора учебника японского языка в рамках обучения межкультурной коммуникации (средний этап, языковой ВУЗ) // Вопросы науки и образования 2018. С. 149-152 [Электронный ресурс]. URL: https://cyberleninka.ru/article/n/problema-vybora-uchebnika-yaponskogoyazyka-v-ramkah-obucheniya-mezhkulturnoy-kommunikatsii-sredniy-etapyazykovoy-vuz.

13. Genki [Электронный pecypc]. URL: https://genki3.japantimes.co.jp/ (дата обращения 07.05.2021).

14. Лазарева Д.С. О постановке курса иероглифики как практикума к базовому курсу японского языка // Японский язык в вузе: актуальные проблемы преподавания под редакцией: Л. Т. Нечаева. № 13.2015. С. 77-88. [Электронный ресурс]. URL: https://publications.hse.ru/chapters/145748807 (дата обращения 07.05.2021).

15. Майдонова С.В., Ядрышникова М.В. Японский язык. 6 класс. Учебное пособие для учащихся общеобразовательных учреждений. М.: Вентана-Граф, 2013. 160 с.

16. Marugoto [Электронный pecypc]. URL: www.marugoto.org (дата обращения 07.05.2021).

17. Shigemori Bučar Chikako, Hyeonsook Ryu, Nagisa Moritoki Škof, Kristina Hmeljak Sangawa The CEFR and teaching Japanese as a foreign language // Cadre européen commun de référence pour les langues - regards croisés Vol 54 № 1 (2014). [Электронный pecypc]. URL: https://revije.ff.unilj.si/linguistica/article/view/2619 (дата обращения 07.05.2021).

18. Исправникова И.В. Система обучения японскому языку в условиях дополнительного образования (уровень начального основного образования) // Вестник науки и образования № 9 (87) часть 1 2020. С. 71-74. [Электронный pecypc]. URL: https://cyberleninka.ru/article/n/sistema-obucheniya-yaponskomuyazyku-v-usloviyah-dopolnitelnogo-obrazovaniya-uroven-nachalnogo-osnovnogoobrazovaniya (дата обращения 07.05.2021). 